\title{
EXTRAÇÃO E CARACTERIZAÇÃO DO AMIDO DE INHAME E DESENVOLVIMENTO DE FILMES COMESTÍVEIS ANTIMICROBIANOS
}

\section{EXTRACTION AND CARACTERIZED OF YAM STARCH AND DEVELOPMENT ANTIMICROBIAN EDIBLES FILMS}

\author{
Alba M. Durango. ${ }^{1,2}$, Nilda De F. F. Soares. ${ }^{2}$, Nelio J. Andrade. ${ }^{2}$
}

\begin{abstract}
RESUMO
O objetivo deste trabalho foi extrair e caracterizar o amido do inhame Dioscorea alata e desenvolver filmes antimicrobianos. O amido foi extraído e determinado sua composição físicoquímica e propriedades reológicas. Foram preparados filmes de $4 \%$ de amido $(\mathrm{p} / \mathrm{p})+2 \%$ de glicerol (p/p) y filmes de amido + glicerol + quitosana em concentrações de 0,5; 0,75; 1,0 e 1,5\% pelo método "casting" e determinadas suas permeabilidades ao vapor de água. $\mathrm{O}$ rendimento do processo de extração foi de 9,3\%. Os componentes físico-químicos em base seca: $11,57 \%$ para umidade, $0,64 \%$ de proteínas, $0,052 \%$ de matéria graxa e $0,17 \%$ de cinzas. O conteúdo de amido e amilose foram $99,17 \%$ e $22 \%$, respectivamente. A densidade absoluta foi de $1,522 \mathrm{~g} \mathrm{~mL}^{-1}$. Os índices de absorção de água e solubilidade a temperatura ambiente foram de 1,84 e 0,46, respectivamente, aumentando para 15,76 e 19,32 em temperatura de $100{ }^{\circ} \mathrm{C}$. A temperatura inicial de pasta foi de $60,3{ }^{\circ} \mathrm{C}$ e a máxima temperatura de viscosidade foi de $98,5{ }^{\circ} \mathrm{C}$, apresentando baixa tendência a retrogradação (100 UA). Os filmes produzidos foram visualmente transparentes com espessuras de $30 \pm 5 \mu \mathrm{m}$. Os valores de permeabilidade dos filmes foram estatisticamente diferentes $(P r<0,05)$, com valores de 4,58 $\mathrm{g} \mathrm{mm} \mathrm{kPa}^{-1} \mathrm{~d}^{-1} \mathrm{~m}^{-2}$, para 0 filme de amido + glicerol, e 3,57 $\mathrm{g} \mathrm{mm} \mathrm{kPa}^{-1} \mathrm{~d}^{-1} \mathrm{~m}^{-2}$, para o filme de amido + glicerol $+1,5 \%$ de quitosana, diminuindo esta com o aumento do teor de quitosana. $\mathrm{O}$ amido de inhame representa uma boa fonte para a produção de filmes comestíveis com grande potencial de aplicação na indústria de alimentos.
\end{abstract}

Palavras Chave: Dioscorea alata, isolamento do inhame, filmes ativos.

\begin{abstract}
Dioscorea alata starch antimicrobial films were developed and characterized from yam starch and development. Films were prepared with $4 \%$ yam starch $(\mathrm{p} / \mathrm{p})+2 \%$ glycerol $(\mathrm{p} / \mathrm{p})$, $4 \%$ yam starch $(\mathrm{p} / \mathrm{p})+2 \%$ glycerol $(\mathrm{p} / \mathrm{p})$ added with $0,5,0,75,1,0$ and 1,5 \% chitosan. Films vapor permeabilities were determined. The starch showed the following characteristics: 9,3\% yield, $11,57 \%$ humidity content, $0,64 \%$ proteins, $0,052 \%$ lipids, $0,17 \%$ ash, $99,17 \%$ starch and $22 \%$ amylose. The gel initial temperature was $60,3{ }^{\circ} \mathrm{C}$ and maximum viscosity temperature was 98,5 ${ }^{\circ} \mathrm{C}$, showing a low tendency for retrogradation (100 UA). The $30 \pm 5 \mu \mathrm{m}$ film thickness showed

\footnotetext{
${ }^{1}$ Universidad de Córdoba, Departamento de Ingeniería de Alimentos, Km 12 vía Cereté - Cienaga de Oro, Tel (4) 894 0508.E-mail:adurango@sinu.unicordoba.edu.co

${ }^{2}$ Departamento de Tecnologia de Alimentos, Universidade Federal de Viçosa, Viçosa-MG. Brazil.
} 
transparency. The permeability values showed significant $(\operatorname{Pr}<0,05)$ difference among them, vapor permeability ranged from 4,58 g.mm.dia ${ }^{-1} \mathrm{~m}^{-2} \mathrm{KPa}^{-1}$ for starch-glycerol film to 3,57 g mm $\mathrm{dia}^{-1} \mathrm{~m}^{-2} \mathrm{KPa}^{-1}$ for the film containing $1,5 \%$ of chitosan + starch + glycerol. The film permeability decreased as the chitosan level in the film increased. The yam starch is a good source for production of edible film with a potential for food industry.

Key-words: Dioscorea alata, yam starch, active films

\section{INTRODUÇÃO}

Dentre os polissacarídeos utilizados para produção de filmes e revestimentos comestíveis, o amido é o biopolímero natural mais empregado. O uso do amido pode ser uma interessante alternativa para filmes e revestimentos comestíveis devido ao seu fácil processamento, baixo custo, abundância, biodegradabilidade, comestibilidade e fácil manipulação (Mali et al., 2002). O amido é um dos polissacarídeos mais importantes e abundantes na natureza e tem sido objeto de numerosas investigações que reportam, entre outras, sua capacidade para formar revestimentos para aplicação na indústria de alimentos (Arvanitoyannis et al., 1998). É obtido em forma granular de fontes renováveis como milho, mandioca, batata, inhame, cereais e legumes, sendo apropriado para uma variedade de usos na indústria (Petersen et al., 1999) .

O amido é formado por dois tipos de polímeros da glicose: amilose e amilopectina (Lehninger et al., 1995), a relação destes dois componentes varia de acordo com o tipo de amido, mas normalmente os amidos contêm entre 18 a 30\% de amilose. O conteúdo de amilose no amido é uma propriedade muito importante quando se deseja preparar filmes. Quanto maior o teor de amilose melhor será a qualidade do filme formado (Petersen et al., 1999). Em estudos feitos por Lawton (1996), foi observado que os filmes e revestimentos à base de amido apresentam diferentes propriedades e estas diferenças são atribuídas ao conteúdo de amilose no amido.

No Brasil, as principais fontes de amido para a indústria de alimentos são milho (Zea mays) e mandioca (Manihot utilissima). O inhame (Dioscorea sp) é considerado como uma fonte alternativa, pelas características tecnológicas desejáveis de seu amido como, estabilidade às altas temperaturas e sob valores baixos de pH (Alves et al., 1999). O inhame pertence à família Dioscoreaceae, gênero Dioscorea, e as espécies mais cultivadas são Dioscorea alata L., Dioscorea rotundata L. e a Dioscorea cayennensis Lamb. Esta última plantada no litoral 
nordestino (Anuário, 1994; Santos, 1996). O inhame é uma amilácea bastante cultivada para o consumo direto. Segundo Leonel e Cereda (2002), o inhame apresentou o maior rendimento na produção de amido por área $\left(6,1\right.$ ton ha $\left.{ }^{-1}\right)$ entre as espécies estudadas.

O inhame é composto, principalmente, de amido com pequenas quantidades de proteínas, lipídeos e muitas vitaminas como $A, B_{1}, B_{2}, B_{6}$, vitamina $C$ e rico em minerais (Omonigho e Ikenebomeh, 2000). Seu amido é semelhante ao amido do milho, em sabor, textura e cor. A farinha pode ser adicionada à do trigo para a fabricação de pães ou pode ser usada em diversos pratos, doces ou salgados (Abramo, 1990). O amido de inhame apresenta ótimas qualidades, podendo ser amplamente empregado na indústria de tecidos, colas, glicoses e produtos panificáveis. Algumas espécies de inhame têm sido cultivadas com finalidade farmacológicas para obtenção de material para síntese de cortisona e hormônios esteróides.

O filme é uma película fina formada separadamente do alimento e posteriormente aplicada sobre o mesmo (Gennadios e Weller, 1990). Agem como uma barreira, protegendo o alimento dos elementos externos, como umidade, óleo, vapor orgânico e desta forma estende sua vida de prateleira (Guilbert et al., 1996; Krochta e Demulder-Johnston, 1997; Klahorst, 1999).

Uma das principais funções das embalagens nos alimentos é evitar ou diminuir a transferência de umidade entre o alimento e a atmosfera circundante. Por isso a permeabilidade ao vapor de água deve ser o mais baixa possível (Gontard et al., 1992). A eficiência funcional dos filmes comestíveis depende de sua composição. Por possuir caráter hidrofílico, as embalagens à base de amido apresentam baixas propriedades de barreira ao vapor de água. Entretanto, estratégias vêm sendo desenvolvidas para melhorar a estabilidade dos filmes à umidade (Petersen et al., 1999). A adição de plastificantes, como o sorbitol e glicerol, na formulação de filmes a base de amido de milho e de batata, com diferentes conteúdos de amilose, melhorou suas propriedades de barreira ao vapor de água (García et al., 1999). A adição de lipídeos nos filmes à base de polissacarídeos melhora as propriedades de barreira devido a aumento da hidrofobicidade na embalagem (García et al., 2000). 
Mali et al. (2002), constataram que os filmes à base de amido de inhame (3,3\% p/p de amido e $2 \% \mathrm{p} / \mathrm{p}$ de glicerol) apresentam uma matriz homogênea, com estrutura estável à condições ambientais e uma permeabilidade a vapor de água de $1,55 \times 10^{-10} \mathrm{~g} \mathrm{~m}^{-1} \mathrm{~s}^{-1} \mathrm{~Pa}^{-1}$ a $25^{\circ} \mathrm{C}$ e $75 \%$ de umidade relativa (UR). Esse resultado foi muito menor que os apresentados por outros filmes comestíveis à base de glúten de trigo/glicerol $\left(\begin{array}{cccccccc}7,0 & \mathrm{x} & 10^{-10} & \mathrm{~g}^{-1} & \mathrm{~m}^{-1} & \mathrm{~Pa}^{-1}\end{array}\right)$ e hidroxipropilmetilcelulose/glicerol $\left(1,9 \times 10^{-10} \mathrm{~g} \mathrm{~m}^{-1} \mathrm{~s}^{-1} \mathrm{~Pa}^{-1}\right)$ nas mesmas condições de temperatura e de umidade relativa. Segundo Mali et al. (2002), o inhame (Dioscorea sp) constitui uma boa fonte de amido para a produção de filmes comestíveis, já que seu amido contém aproximadamente, $30 \%$ de amilose.

O objetivo deste trabalho foi extrair e caracterizar o amido de inhame (Dioscorea alata), variedade Caramujo, desenvolver filmes comestíveis antimicrobianos a partir desse amido e determinar a sua permeabilidade ao vapor de água dos mesmos.

\section{MATERIAL E MÉTODOS}

\section{Extração e caracterização do amido de inhame}

O experimento foi conduzido no Laboratório de Amido e Farinha e Laboratório de Análises de Alimentos da Universidade Federal de Viçosa, Viçosa-MG, Brasil.

\section{Matéria prima}

Foi utilizado o inhame (Dioscorea alata), variedade Caramujo, registrado no Banco de Germoplasma da UFV com o código BGH 7270 e cultivado na Horta de Pesquisa do Departamento de Fitotecnia da Universidade Federal de Viçosa. As amostras de inhame foram coletadas aos 10 meses de cultivo. Foram selecionados tubérculos sadios, livres de injúrias mecânicas e defeitos fitossanitários, os quais foram armazenados por 24 horas, em câmara fria a 5 $\pm 1{ }^{\circ} \mathrm{C}$.

\section{Extração do amido}

A extração foi realizada segundo a metodologia de Cruz e EL Dash (1984), com adaptações. A trituração do amido foi feita no liquidificador industrial e o tempo de decantação foi de 
aproximadamente 24 horas a $4{ }^{\circ} \mathrm{C}$, pela presencia de mucilagens que dificulta o processo de decantação. Depois de seco, o amido foi triturado e peneirado em malhas de 200 mesh.

\section{Composição físico-química}

Foram determinados os teores de umidade, proteínas, lipídeos, cinzas, pH e acidez titulável pelo método standard da AOAC (1995). Os teores de amido e de amilose foram determinados segundo metodologia descrita por Cereda (2001).

\section{Índice de absorção de água e índice de solubilidade}

Os índices de absorção de água e de solubilidade foram determinados com soluções de 5\% de amido nas temperaturas de $25{ }^{\circ} \mathrm{C}$ (ambiente), $50{ }^{\circ} \mathrm{C}, 75{ }^{\circ} \mathrm{C}$ e $100{ }^{\circ} \mathrm{C}$ segundo a metodologia de Schoch (1964).

\section{Densidade absoluta}

A densidade absoluta do amido foi determinada segundo o método de deslocamento de líquido, à temperatura ambiente, empregando-se xileno (Schoch e Leach, 1964).

\section{Propriedades visco-amilográficas}

A viscosidade da pasta foi estudada em soluções aquosas de amido a 6\%, utilizando Viscoamilográfo Brabender, com agitação constante de $75 \mathrm{rpm}$ e temperatura inicial de $25{ }^{\circ} \mathrm{C}$ com incremento de $1,5{ }^{\circ} \mathrm{C}$ por minuto, seguindo-se o método AACC 22-10 (1982). Para avaliação das propriedades do amido foram determinados os parâmetros de temperatura inicial da pasta, viscosidade máxima, temperatura de viscosidade máxima, viscosidade mínima à temperatura constante, viscosidade final, quebra (“shear thinning”) e tendência à retrogradação (“set back").

\section{Consistência do gel}

Foi determinada em suspensões de amido a $6 \%$ gelatinizadas e incubadas a $25^{\circ} \mathrm{C}$ (ambiente) e a $4{ }^{\circ} \mathrm{C}$ por cinco dias. As leituras foram feitas com o penetrômetro e o enrijecimento do gel foi expresso em $\mathrm{mmcm}^{-2}$. 


\section{Ciclo de congelamento e descongelamento}

Foi feito com uma suspensão de 4\% de amido, gelatinizada e resfriada até a formação do gel, e após, distribuídos em 10 tubos plásticos, previamente pesados. Os tubos foram divididos em dois grupos (A e B) e estocados a $-20{ }^{\circ} \mathrm{C}$ por cinco dias. Diariamente, um tubo do grupo $\mathrm{A}$, foi retirado do freezer, deixado à temperatura ambiente, por uma hora e centrifugado a 3500 rpm por 15 minutos. O sobrenadante foi descartado e o tubo pesado para calcular a perda de água. Procedimento similar foi realizado com o grupo B, sendo que diariamente todos os tubos deste grupo eram retirados do freezer e após uma hora, um tubo era centrifugado e os demais retornavam ao freezer.

\section{Elaboração de filmes comestíveis}

Para a elaboração dos filmes comestíveis antimicrobianos foi usado amido de inhame (Dioscorea alata, var. Caramujo) extraído no Laboratório de Amido da UFV e quitosana como composto antimicrobiano, com grau de desacetilação acima de 85\%, produzida pela Padetec, Fortaleza, Ceará. Foram elaborados cinco tipos de filmes a partir de suspensões aquosas de amido, glicerol e quitosana. Suspensões de $4 \%$ de amido (p/p) e $2 \%$ (p/p) de glicerol (concentrações definidas em testes prévios) foram gelatinizadas em amilógrafo Brabender, por 45 minutos, sob agitação constante de $75 \mathrm{rpm}$ e temperatura inicial de $25{ }^{\circ} \mathrm{C}$, com incremento de 1,5 ${ }^{\circ} \mathrm{C}$ por minuto, mantendo-se a $95{ }^{\circ} \mathrm{C}$ durante 10 minutos, seguido de resfriamento. Após essa etapa, foi adicionada quitosana nas concentrações de 0,0;0,5;0,75; 1,0 e 1,5\% (p/p), previamente dissolvida em solução de ácido acético glacial 0,4\% (concentração definida em testes prévios). As suspensões foram homogeneizadas em agitador Ultra Turrax T 18 basic a 10.000 rpm por 10 segundos. Os filmes foram formados por processo "casting”, sobre placas de acrílico quadradas de $30 \mathrm{~cm}$ x $30 \mathrm{~cm}$, e secados em estufa a $60^{\circ} \mathrm{C}$, durante ocho horas. Os filmes foram removidos da placa e condicionados a $25{ }^{\circ} \mathrm{C}$ e umidade relativa de $75 \%$ para testes posteriores.

\section{Determinação da espessura}

A espessura dos filmes foi determinada com um micrômetro Mitutoyo (0 a 25 mm e precisão de 0,01 mm). Foram efetuadas cinco medições em posições diferentes do filme, usando-se a média como a medida final da espessura. 


\section{Determinação da permeabilidade ao vapor de água}

Os filmes foram condicionados a $25{ }^{\circ} \mathrm{C}$ e UR de $75 \%$, por 72 horas. O teste de permeabilidade foi realizado segundo a metodologia da ASTM (1995) método E96-95. Os filmes foram cortados em círculos do mesmo diâmetro da cápsula $(7,5 \mathrm{~cm})$ e depois selados, com parafina, na borda da cápsula que continha cloreto de cálcio anidro ( $0 \%$ de UR). As cápsulas foram pesadas em balança analítica e colocadas em dessecadores contendo solução saturada de cloreto de sódio (UR de $75 \%)$. Os dessecadores foram colocados em uma câmara a $25^{\circ} \mathrm{C}$. As cápsulas foram pesadas a cada 12 horas até peso constante. As mudanças no peso foram plotadas em função do tempo. Mediante a inclinação da reta, obtida por regressão linear, determinou-se a taxa de

permeabilidade que foi igual à inclinação da reta $\left(\mathrm{g}^{-1}\right)$ dividida pela área da cápsula $\left(\mathrm{m}^{2}\right)$. A taxa de permeabilidade ao vapor de água (TPVA) foi expressa em g água $\mathrm{dia}^{-1} \mathrm{~m}^{-2}$. A permeabilidade foi determinada mediante a fórmula $\mathrm{P}=$ TPVA espessura/ps $\left(\mathrm{UR}_{1}-\mathrm{UR}_{2}\right)$, onde ps é a pressão de saturação de vapor à temperatura do ensaio $\left(25^{\circ} \mathrm{C}\right), \mathrm{UR}_{1}$ é a umidade relativa do dessecador e $\mathrm{UR}_{2}$ é a umidade relativa no interior da cápsula. A permeabilidade foi expressa em $\mathrm{g} \mathrm{mm} \mathrm{dia} \mathrm{m}^{-1} \mathrm{~m}^{-2}$ $\mathrm{kPa}^{-1}$.

\section{Delineamento Experimental e Análise estatística}

O delineamento experimental foi inteiramente casualizado. Todas as análises do amido foram realizadas em três repetições. Para as análises físico-químicas do amido, foi feita análise estatística descritiva, obtendo-se como valor final de cada análise a média das repetições, com seus respectivos desvios padrões. Para o teste de permeabilidade do filme foram feitas quatro repetições, foi utilizada análise de variância e análise de regressão, ao nível do 5\% de probabilidade.

\section{RESULTADOS E DISCUSSÃO}

\section{Extração do amido de inhame}

Neste experimento, o rendimento da extração de amido do inhame foi de 9,3\%, rendimento considerado baixo quando comparado ao de outras tuberosas como, por exemplo, a mandioca, que apresenta um rendimento de extração industrial entre 25 a 28\% (Cereda, 2001). Este foi, porém, semelhante aos 10\% obtido por Daiúto e Cereda (2003), em condições de laboratório, 
utilizando extração natural com água, na proporção 2:1 de sólido. No caso do inhame, o processo de extração de amido é influenciado pela presença de mucilagem nos tubérculos, que aumenta a viscosidade e dificulta a passagem pelas peneiras, ocasionando o aumento do tempo de decantação, o que dificulta a recuperação do amido. A mucilagem no inhame está formada de polissacarídeos não amiláceos (PNA), esses PNA são proteínas-arabinogalactanas e muito deles têm função de componente da parede celular (Daiúto e Cereda, 2003).

\section{Composição físico-química}

Os dados da composição físico-química do amido de inhame, quanto à umidade, matéria graxa, cinzas e conteúdo de amilose (Tabela 1), são comparáveis aos citados por Emiola e Delarosa (1981), para amido de inhame de quatro espécies de Dioscorea (D. alata, D. cayenensis, D. dumetorum e D. rotundata)

O teor de proteínas do amido de inhame neste experimento foi maior do que o teor de 0,2\% reportado por Alves et al. (1999) e Mali et al. (2002) para D. alata. Daiúto e Cereda (2003) reportam 0,39\% de proteína em base seca para amido da mesma espécie, extraído com água. O baixo conteúdo de matéria graxa no amido é considerado uma característica desejável, por permitir a estocagem do produto por longos períodos de tempo, sem o risco de rancificação (Emiola e Delarosa, 1981). Nesta pesquisa o conteúdo de amido do inhame foi semelhante aos resultados reportados por Mali et al. (2002), porém superior ao resultado de Emiola e Delarosa (1981), para D. alata, que foi de 88\%. O conteúdo de amilose foi comparável ao citado por Daiúto e Cereda (2003) e inferior aos resultados de Mali et al. (2002) para D. alata, que foi de 30\%. As diferenças na composição físico-química do amido de inhame podem ser explicadas

pelas diferentes condições de cultivo e obtenção do tubérculo e pelos procedimentos analíticos utilizados.

\section{Caracterização do amido}

As propriedades de pasta do amido são de particular interesse na maioria das aplicações industriais. Na indústria alimentícia a temperatura de gelatinização, poder de inchamento, viscosidade e estabilidade da pasta são de grande importância e determinam a utilização do amido. 
Os Índices de absorção de água e de solubilização do amido de inhame a $25{ }^{\circ} \mathrm{C}$ (temperatura ambiente), $50{ }^{\circ} \mathrm{C}, 75^{\circ} \mathrm{C}$ e $100{ }^{\circ} \mathrm{C}$ (Tabela 2), foram semelhantes aos reportados por Emiola e Delarosa (1981).

O IAA a $25{ }^{\circ} \mathrm{C}$ e $50{ }^{\circ} \mathrm{C}$ foi semelhante. No entanto, ao aumentar a temperatura para $75{ }^{\circ} \mathrm{C}$ e 100 ${ }^{\circ} \mathrm{C}$, observou-se um aumento nos valores do IAA e do IS, mostrando que os grânulos do amido de inhame (Dioscorea alata), variedade Caramujo, tem grande capacidade de absorção de água e resistência à ruptura. Segundo Ciacco e Cruz (1982), a conseqüência direta do intumescimento é o aumento na solubilidade, claridade e viscosidade da pasta do amido.

A densidade absoluta do amido de inhame (Dioscorea alata), variedade Caramujo foi de 1,522 \pm 0,009g mL $\mathrm{gL}^{-1}$, valor comparável ao valor 1,513 $\mathrm{g} \mathrm{mL}^{-1}$, citado por Emiola e Delarosa (1981), para D. alata. A densidade do amido é de fundamental importância para propósitos tecnológicos. Este parâmetro representa o conteúdo de material, por unidade de volume real ocupado pelo material (Schoch e Leach, 1964).

As propriedades viscoamilográficas do amido de inhame, em suspensões de 6\% de amido estão apresentadas na tabela 3. A temperatura inicial de pasta foi um pouco menor que a reportada por Emiola e Delarosa (1981) para D. alata que foi de $65^{\circ} \mathrm{C}$. Daiúto e Cereda (2003) reportam um “setback" (tendência à retrogradação) de 129,58 para amido de inhame de D. alata, isolado com água, maior que o observado neste trabalho.

Foi avaliada a tendência à retrogradação do gel de amido de inhame preparado a partir de uma suspensão a 6\%. A retrogradação é responsável pelo encolhimento, sinérese, e endurecimento de géis de amido conservados por determinado período, principalmente à temperatura de refrigeração. Estes efeitos são mais evidenciados quando o gel é congelado e descongelado por várias vezes. Embora os efeitos da retrogradação sejam indesejáveis para a maioria dos produtos alimentícios, existem alguns casos onde a ocorrência deste fenômeno é benéfica, por exemplo, em aplicações indústrias onde é necessária a formação de um filme insolúvel (Ciacco e Cruz, 1982). Neste trabalho, o aumento da firmeza do gel, medido com o penetrômetro, e a opacidade dos géis formados foram evidências da ocorrência de retrogradação. $\mathrm{O}$ endurecimento do gel foi 
maior nas amostras mantidas na geladeira, do que naquelas mantidas à temperatura ambiente. Aparentemente, os géis armazenados à temperatura ambiente sofreram degradação progressiva, provavelmente enzimática, fazendo com que os géis se apresentassem menos firmes com o tempo. Contrariamente, os géis armazenados sob refrigeração mostraram aumento da rigidez com o tempo, evidenciando o avanço da retrogradação.

No ciclo de congelamento e descongelamento para amido de inhame, observou-se uma tendência à perda de água com o aumento do tempo. Os géis de amido de inhame mostraram estabilidade ao congelamento até cuatro dias de armazenamento, a partir do qual houve aumento acentuado da sinérese. Os géis de amido que foram descongelados todos ao mesmo tempo e novamente congelados, exibiram intensa perda de água já a partir do primeiro dia de armazenamento, mostrando que os ciclos de congelamento-descongelamento favoreceram o envelhecimento do gel.

\section{Produção de filmes comestíveis e permeabilidade ao vapor de água}

Os filmes produzidos se apresentaram visualmente transparentes. A espessura dos filmes foi de $30 \pm 5 \mu \mathrm{m}$. Segundo a análise de variância as permeabilidades dos revestimentos foram estatisticamente significativas $(\operatorname{Pr}<0,05)$.

Segundo a análise de regressão, o filme de amido com 2\% de glicerol e 0,0\% de quitosana apresentou maior permeabilidade ao vapor de água em relação aos outros filmes (Figura 1). A ausência de quitosana nesse filme pode ter possibilitado maior ação plastificante das moléculas de glicerol nas cadeias poliméricas do amido, aumentando assim, a permeabilidade ao vapor de água do filme. Além disso, o caráter hidrofílico do glicerol favorece a absorção e desorção das moléculas de água (Mali et al., 2004).

O filme de amido e glicerol apresentou permeabilidade ao vapor de água de 4,58 $\mathrm{g} \mathrm{mm} \mathrm{kPa}^{-1} \mathrm{~d}^{-1}$ $\mathrm{m}^{-2}\left(0,529 \times 10^{-10} \mathrm{~g} \mathrm{~m}^{-1} \mathrm{~s}^{-1} \mathrm{~Pa}^{-1}\right)$, menor que a reportada por Mali et al. (2002) que foi de 1,81 $\mathrm{x}$ $10^{-10} \mathrm{~g} \mathrm{~m}^{-1} \mathrm{~s}^{-1} \mathrm{~Pa}^{-1}$. Mali et al. (2004), também reportaram permeabilidade ao vapor de água de 1,395 x $10^{-10} \mathrm{~g} \mathrm{~m}^{-1} \mathrm{~s}^{-1} \mathrm{~Pa}^{-1}$ para filmes com 4\% de amido e $2 \%$ de glicerol. Estes dados diferentes podem ser atribuídos à maior espessura dos filmes usados por esses autores. Os filmes 
hidrofílicos apresentam aumento na permeabilidade ao vapor de água com o aumento da espessura (Hagenmaier e Shaw, 1990; Mchugh et al., 1993). Park e Chinnan (1995) reportam que este comportamento anômalo ocorre porque os componentes hidrofílicos absorvem água ocasionando mudanças estruturais nos filmes com diferentes espessuras.

Neste trabalho, a permeabilidade ao vapor de água dos filmes foi influenciada pelo conteúdo de quitosana, observando-se diminuição da permeabilidade ao aumentar o conteúdo de quitosana. O filme de amido adicionado de 1,5\% de quitosana, apresentou a menor permeabilidade ao vapor de água $\left(3,57 \mathrm{~g} \mathrm{~mm} \mathrm{kPa}^{-1} \mathrm{~d}^{-1} \mathrm{~m}^{-2}\right)$. este resultado pode ser decorrente da maior concentração de grupos aminos na matriz polimérica da quitosana, além da sua baixa solubilidade em água. A permeabilidade deste filme foi menor que a de outros filmes comestíveis hidrofílicos como o de glúten/glicerol com 53,2 g mm kPa ${ }^{-1} \mathrm{~d}^{-1} \mathrm{~m}^{-2}$ (Park e Chinnan, 1990, citado por Mchugh et al., 1996), filmes a base de purê de pêssego com 57,8 $\mathrm{g} \mathrm{mm} \mathrm{kPa} \mathrm{m}^{-1} \mathrm{~m}^{-2}$ (Mchugh et al (1996), filmes de hidroxipropilmetilcelulose (HPMC) com 9,1 g mm kPa ${ }^{-1} \mathrm{~d}^{-1} \mathrm{~m}^{-2}$ (Hagenmaier e Shaw, 1990) e menor que a apresentada pelo celofane de $7,3 \mathrm{~g} \mathrm{~mm} \mathrm{kPa}^{-1} \mathrm{~d}^{-1} \mathrm{~m}^{-2}$ (Taylor, 1986, citado por Mchugh et al., 1996). Esse mesmo filme quando comparado com os filmes sintéticos apresentou uma maior permeabilidade ao vapor de água, como o Polietileno de Baixa Densidade (PEBD) que apresenta uma permeabilidade de 0,079 $\mathrm{g} \mathrm{mm} \mathrm{kPa}^{-1} \mathrm{~d}^{-1} \mathrm{~m}^{-2}$ e Etileno Vinil álcool $(E V O H)$ que apresenta $0,25 \mathrm{~g} \mathrm{~mm} \mathrm{kPa}^{-1} \mathrm{~d}^{-1} \mathrm{~m}^{-2}$ de permeabilidade ao vapor de água (Mchugh e Krochta, 1994)).

\section{CONCLUSÕES}

Embora a extração do amido de inhame tenha apresentando baixo rendimento, o inhame representa uma boa fonte de amido. O amido de inhame Caramujo apresentou resultados compatíveis com os reportados na literatura com bom conteúdo de amilose, que é componente importante na formação de filmes. Os filmes de amido de inhame e amido adicionado de quitosana apresentaram visualmente boa transparência, com permeabilidade ao vapor de água menor que a de outros filmes comestíveis. O filme de amido com 1,5\% de quitosana apresentou a menor permeabilidade ao vapor de água dentre os filmes testados. 
Considerando suas propriedades físico-químicas e reológicas, o amido de inhame mostrou ser boa fonte para a produção de filmes comestíveis com grande potencial de aplicação na indústria de alimentos, com a vantagem de serem biodegradáveis.

\section{BIBLIOGRAFIA}

Abramo, M. 1990. Taioba, cará e inhame: o grande potencial inexplorado. Ícone, São Paulo, 80 p.

Alves, R., Grossmann, M. y Silva, R. 1999. Gelling properties of extruded yam (Dioscorea alata) starch. Food Chemistry 67:123-127.

AACC (AMERICAN ASSOCIATION OF CEREAL CHEMISTS). 1982. Approved Methods of the AACC. St. Paul, AACC, p22-10.

ASTM (AMERICAN SOCIETY FOR TESTING AND MATERIALS). 1995. Standards test methods for water vapor tansmission of materials - E - 95. ASTM, Philadelphia, 8p.

ANUÁRIO A GRANJA DO ANO. 1994. Cará e Inhame. Centaurus, São Paulo, p30-35.

AOAC (ASSOCIATION OF OFFICIAL ANALYTICAL CHEMISTRY). 1995. Official Methods of Analysis. 16 ${ }^{\text {th }}$ ed. Arlington, TX: Association of official Analytical Chemistry. Vol. 2.

Arvanitoyannis, I.; Nakayama, A. y Aiba, S. 1998. Edible films made from hydroxypropyl starch and gelatin and plasticized by polyols and water. Carbohydrate Polymers 36:105119.

Cereda, M. 2001. Culturas de Tuberosas Amilâceas Latino Americanas. Cargill, São Paulo, Vol. 2. p511-518.

Ciacco, C. y Cruz, R. 1982. Fabricação de amido e sua utilização. Série Tecnologia Agroindustrial, Secretaria de Indústria, Comércio, Ciência e Tecnologia, São Paulo, 152p.

Cruz, R. y EL Dash, A. A. 1984. Isolamento e caracterização de amido de chuchu. Revista Ceres 31(175):173-188.

Daiúto, E. y Cereda, M. 2003. Extração de fécula inhame (Dioscorea sp). En: Cereda, M. y Vilpoux, O. (Eds). Culturas de Tuberosas Amilâceas Latino Americanas. Cargill, São Paulo, p177-190.

Emiola, L. y Delarosa, L. 1981. Physicochemical characteristics of yam starches. Journal of Food Biochemistry 5:115-130.

García, M., Martino, M. y Zaritzky N. 1999. Edible starch Films and coatings characterization: scanning electron microscopy, water vapor, and gas permeabilities. Scanning 21(5):348353.

García, M., Martino, M. y Zaritzky N. 2000. Lipid addition to improve barrier properties of edible starch-based films and coatings. Journal of Food Science 65(6):941-947. 
Gennadios, A. y Weller, C. 1990. Edible films and coatings from wheat and corn proteins. Food Technology 44(10):63-69.

Gontard, N., Guilbert, S., y Cuq, B. 1992. Edible wheat gluten films: influence of the main process variables on film properties using response surface methodology. Journal of Food Science 57(1):190-195.

Guilbert, S., Gontard, N. y Gorris G. 1996. Prolongation of the shelf-life of perishable food products using biodegradable films and coatings. Lebensmittel- Wissenschoft undTechnologie 29(1-2):10-17.

Hagenmaier, R. y Shaw, P. 1990. Moisture permeability of edible films made with fatty acid and hydroxypropyl methylcellulose. Journal of Agriculture Food Chemistry 38:17991803.

Klahorst, S. 1999. Applications: Credible Edible Films. Food Product Design 9(1):1-6.

Krochta, J. y Demulder-Johnston C. 1997. Edible and biodegradable polymer films: challengers and opportunities. Food Technology 51(2):61-74.

Lawton, J. 1996. Effect of starch type on the properties of starch containing films. Carbohydrate Polymers 29:203-208.

Lehninger, A.; Nelson, D. y Cox, M. 1995. Princípios de Bioquímica. Sarvier, São Paulo, 839 p.

Leonel, M.; Cereda, M. 2002. Caracterização físico-química de algumas tuberosas amiláceas. Ciência e Tecnologia de Alimentos 22(1).

Mali, S.; Grossmann, M.; García, M.; Martino, M. y Zaritzky N. 2002. Microstructural characterization of yam starch films. Carbohydrate Polymers 50:379-386.

Mali, S.; Grossmann, M.; García, M.; Martino, M. y Zaritzky N. 2004. Barrier, mechanical and optical properties of plasticized yam starch films. Carbohydrate Polymers 56(2):129135.

Mchugh, T.; Avena-Bustillos, R. y Krochta, J. 1993. Hydrophilic edible films: modified procedure for water vapor permeability and explanation of thickness effects. Journal of Food Science 58(4):899-903.

Mchugh, T. y Krochta, J. 1994. Permeability Properties of Edible Films. En: Krotcha, J.; Baldwin, E. y Nisperos-Carriedo, M. (Ed). Edible Coatings and Films to Improve Food Quality. Technomic, Pennsylvania, 379 p.

Mchugh, T.; Huxsoll, C. y Krochta, J. 1996. Permeability properties of fruit puree edible films. Journal of Food Science 61(1):88-91.

Omonigho, S. y Ikenebomeh, M. 2000. Effects of different preservative treatments on the chemical changes of pounded white yam (Dioscorea rotundata) in storage at $28 \pm 2{ }^{\circ} \mathrm{C}$. Food Chemistry 68:201-209.

Park, H. y Chinnan, M. 1995. Gas and water vapor barrier of edible films from protein and cellulose materials. Journal of Food Engineering 25:497-507. 
Petersen, K.; Nielsen, P.; Bertelsen, G.; Lawther, M.; Olsen, M.; Nilsson, N. y Mortensen, G. 1999. Potential of biobased materials for food packaging. Food Science and Technology, 10:52-68.

Santos, E. 1996. Inhame (Dioscorea spp.): aspectos básicos da cultura. EMEPA-PB, SEBRAE, João Pessoa, 158p.

Schoch, T. 1964. Swelling power and solubility of granular starches. En: Whistler, R. y Wolfrom, M. (Ed). Methods in Carbohydrates Chemistry, Academic Press, New York, p106 - 108 .

Schoch, T. y Leach, H. 1964. Determination of Absolute Density. Liquid Displacement. En: Whistler, R. y Wolfrom, M. (Ed). Methods in Carbohydrates Chemistry, Academic Press, New York, p101-103.

Tabela 1. Caracterização físico-química do amido de inhame (Dioscorea alata), variedade Caramujo, em base seca

\begin{tabular}{cc}
\hline Análises & Média (\%) e desvio padrão \\
\hline Umidade & $11,57 \pm 0,08$ \\
Amido & $99,17 \pm 0,76$ \\
Proteínas (N x 6,25) & $0,64 \pm 0,10$
\end{tabular}




$\begin{array}{cc}\text { Matéria graxa } & 0,052 \pm 0,002 \\ \text { Cinzas } & 0,17 \pm 0,02 \\ \text { Amilose } & 22,00 \pm 0,0 \\ \text { pH } & 6,34 \pm 0,06 \\ \text { Acidez titulável } & 1,5 \pm 0,0\end{array}$

Tabela 2. Índice de absorção de água (IAA) e índice de solubilização (IS) do amido de inhame (Dioscorea alata), variedade Caramujo

\begin{tabular}{ccc}
\hline Temperatura $\left({ }^{\mathbf{0}} \mathbf{C}\right)$ & IAA & IS (\%) \\
\hline 25 (Ambiente) & $1,85 \pm 0,009$ & $0,46 \pm 0,02$ \\
50 & $1,89 \pm 0,01$ & $0,92 \pm 0,06$ \\
75 & $6,61 \pm 0,39$ & $7,37 \pm 0,95$
\end{tabular}


Tabela 3. Propriedades viscomilográficas do amido de inhame (Dioscorea alata) variedade Caramujo

\begin{tabular}{cc}
\hline Propriedades Viscomilográficas & Valor \\
\hline Temperatura inicial de pasta $\left({ }^{\circ} \mathrm{C}\right)$ & 60,3 \\
Viscosidade máxima (UA) & 760 \\
\hline
\end{tabular}




\begin{tabular}{cc}
\hline Temperatura de viscosidade máxima $\left({ }^{\circ} \mathrm{C}\right)$ & 98,5 \\
Viscosidade mínima (UA) & 660 \\
Viscosidade final & 760 \\
Quebra (UA) & 100 \\
Setback (UA) & 100 \\
\hline
\end{tabular}




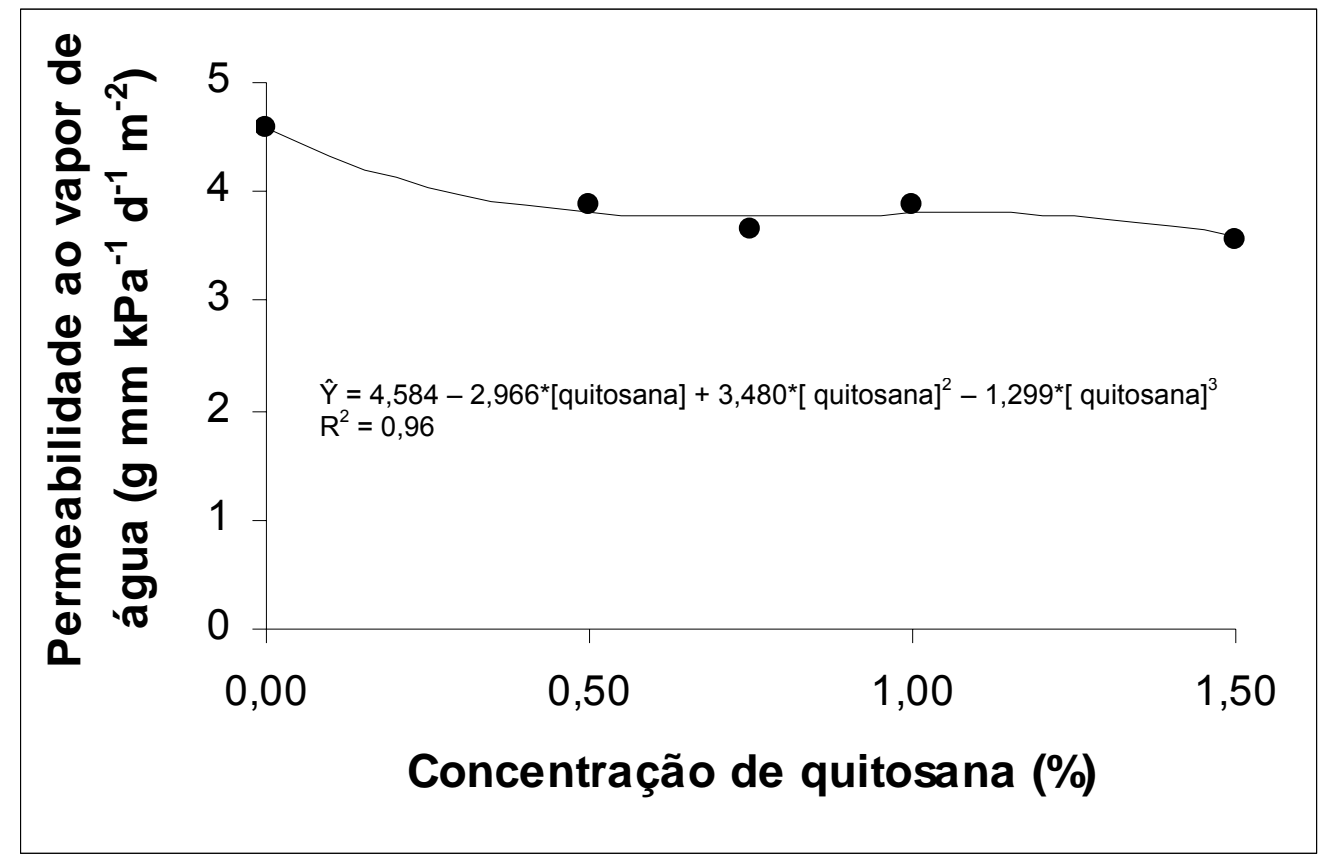

Figura 1. Permeabilidades ao vapor de água dos filmes de amido e quitosana, a $25^{\circ} \mathrm{C}$ e $75 \%$ de umidade relativa com espessura de $30 \pm 5 \mu \mathrm{m}$. 